\title{
Editorial
}

\section{Neue Fundamente für ein europäisches Strafrecht}

In Europa wird kräftig gebaut: auf dem Kirchberg in Luxemburg-Stadt entstehen zwei Türme. Sie gehören zum Europäischen Gerichtshof, der sich vergrößert - personell, räumlich, technisch. Die neuen Bauwerke könnten auch, ja müssten, von symbolischer Bedeutung sein. Die Europäische Union geht mit dem Vertrag von Lissabon einen neuen Schritt: das Strafrecht - ohnehin längst europäisiert -, es wird nicht mehr nur Gegenstand des Pausengesprächs von Kommissions- und Ratsbeamten auf den Fluren des Berlaymontgebäudes in Brüssel sein, sondern wird auch Einzug halten in die kühle Funktionalität und das vornehme Understatement europäischer Gerichtssäle.

Wir haben längst keine Wahl mehr, dass Europa über das Strafrecht entscheidet. Wir haben aber vielleicht noch eine Wahl, wer über es entscheidet - und wo. Vermutlich befindet sich das europäische Strafrecht für einen kurzen Moment auf der Kippe. Dort kommt es darauf an, welche Richtung es nimmt und auf welche Seite seiner Antinomien es sich schlägt. Das Pendel schwankt zwischen einer funktionalen, administrativ gestalteten Integration Europas, das sich des Strafrechts als Instrument bedient, und einem demokratisch kontrollierten, öffentlich diskutierten Strafrecht als Teil eines Europas »von unten «. Es schwankt ferner - das ist bekannt - zwischen der Sicherheit europäischer Kirchhofsruhe und der Freiheit europäischer Aufklärungsdynamik.

Dieses Heft der KritV misst den Ausschlag des Pendels. Es hat die Hand direkt am Puls europäischer Strafrechtsentwicklung. Es enthält Beiträge, die zugleich Dokumente öffentlicher Debatte um Europas Strafrecht sind. Indem es diese Beiträge publiziert, will es die kritische Öffentlichkeit herstellen, die ein demokratisch legitimiertes, rechtsstaatlich und bürgerrechtlich gesichertes europäisches Strafrecht einklagt.

So hat sich der Rechtsausschuss des Deutschen Bundestages am 28.11.2007 mit der Frage beschäftigt »Entsteht ein einheitliches europäisches Strafrecht?«. An diese Frage knüpften sich weitere Erkenntnisinteressen. Sie betrafen die Kompetenzen europäischer Strafgesetzgebung, das institutionelle Rechtsschutzgefüge, die Gewährleistung von Verfahrensgarantien, die Interdependenz von europäischem und staatlichem Strafrecht. Im Einzelnen ging der Ausschuss folgenden Teilfragen nach:

- Woraus ergibt sich dem Grunde nach und in welchem Ausmaß die Kompetenz für die Schaffung eines einheitlichen europäischen Strafrechts: - nach dem Vertrag von Nizza, - nach der Rechtsprechung des EuGH, insbesondere in den Rechtssachen C176/03 (»Umweltstrafrecht«) und C-440/05 (»Meeresverschmutzung «), - nach dem EU-Reformvertrag?

- Ergeben sich aus dem Grundgesetz Schranken, die die Geltung oder Anwendung eines einheitlichen europäischen Strafrechts begrenzen oder verhindern könnten?

- Welche Instanz soll an Hand welchen Maßstabs die Rechtmäßigkeit der Normen eines einheitlichen europäischen Strafrechts überprüfen: - der nationale Gesetzgeber, - die nationalen Gerichte und das Bundesverfassungsgericht, - der EuGH, - der EGMR?

- Vor welchem Gericht und auf welcher Grundlage können Beschuldigte Rechtsschutz erlangen? 
- Welche Auswirkungen auf das nationale Strafrecht sind von einem einheitlichen europäischen Strafrecht zu erwarten?

Bernd Schünemann und Helmut Satzger haben als Sachverständige an der Anhörung mitgewirkt. Ihre Beiträge dokumentieren Kritik und Zweifel an Europas Strafrecht, formulieren aber auch Perspektiven, gar Hoffnung auf ein Strafrecht, das Europa eher verdient hätte. Dabei ist die Kritik von Schünemann eindeutig: Das europäische Strafrecht ist ein undemokratisches, von Prinzipien des tradierten Rechtsgüterschutzes abgehobenes Konstrukt Brüsseler Bürokraten. Auf den Europäischen Gerichtshof vertraut der Autor nicht, wohl eher auf parlamentarische Zügel für die machtvolle europäische Exekutive. Diese will auch Satzger anziehen, ohne jedoch europäischer Gerichtsbarkeit allzu misstrauisch zu begegnen. Im Gegenteil sieht Satzger diese um europäische Fachgerichte in Strafsachen ausbaufähig.

Ist Justizkontrolle der Schlüssel zu einem rechtsstaatlicheren, freiheitlichen Strafrecht in Europa, das Sicherheitsparadigmen und -paranoia der Politik wirksam begrenzt? In Luxemburg haben vom 9. - 11. November 2007 Strafrechtswissenschaftler, Politiker, Richter und Generalanwälte des Europäischen Gerichtshofes sowie EU-Vertreter unter der Frage »Quel contrôle juridictionnel dans l'espace pénal européen? « die Herausforderungen und die Perspektiven europäischen Rechtsschutzes im Strafrecht intensiv und kontrovers diskutiert. Die Konferenz an der Universität Luxemburg wurde von ECLAN (European Criminal Law Academics Network) getragen - einem Netzwerk aus Strafrechtswissenschaft und -praxis, das Vertreter in fast allen Mitgliedstaaten der Europäischen Union hat. Auch hier geht es um europäische Öffentlichkeit, um Kritik am Bestehenden, vor allem aber auch um das massive aufklärerische Interesse an einem praktisch vernünftigen, prinzipiengeleiteten, auf Kerngebiete begrenzten, justizförmigen europäischen Strafrecht. Die in diesem Heft gesammelten Beiträge spiegeln Ausschnitte dieser Konferenz wider und sie zeigen, wie heterogen, wie ungeformt und wie schwach Justizkontrolle in Europa immer noch ist.

Peter-Alexis Albrecht legt diese Schwächen schonungslos dar. Die Prinzipien justizförmiger Kontrolle erleben eine schwere Erosion und sind durch Verpolizeilichung und Informalisierung verursachte Kontrollverluste fast unwiderruflich geschädigt. Auch Katja Sugman und Matjas Jager weisen auf Schwächen europäischer Justiz hin. In den EuGH-Urteilen zum Umweltstrafrecht und zur Meeresverschmutzung werde man den spezifischen Prinzipienanforderungen, die an ein demokratisches Strafrecht zu stellen sind, nicht gerecht. In einem anderen Bereich - dem Prinzip ne bis in idem sieht Christina Karakosta justiziellen Nachholbedarf, dieses Mal freilich auf der Ebene des Europäischen Gerichtshofs für Menschenrechte. Sie macht sich für eine Auslegung des Grundsatzes stark, der ihn zugunsten des Beschuldigtenschutzes voll zur Entfaltung kommen lässt. Stefan Braum moniert große Lücken im System europäischen Datenschutzes. Und schließlich bietet Alexander Cappels Beitrag ein Beispiel dafür, dass sich effektive Justizkontrolle auch nur gegenüber einem sinnvoll begrenzten materiellen Strafrecht entfalten kann. Anhand einer rechtsvergleichenden Betrachtung des Untreuestraftatbestandes entwickelt er eine für Europa ganz ungewohnte Perspektive - die der Entkriminalisierung staatlichen Strafrechts durch gesamteuropäische Regulierung. 
Der Vertrag von Lissabon birgt die Chance zu einer grundlegenden Reflexion europäischer Strafrechtsentwicklung. Diese Reflexion - das zeigen die Beiträge - ist im Gang. Die Politik täte gut daran, sich der Expertise europäischer Netzwerke wie ECLAN im Strafrecht zu vergewissern. Europas Strafrecht braucht neue Fundamente. Es braucht vor allem des grenzübergreifenden Zusammenschlusses Vieler, diese Fundamente zu renovieren und zu bauen. Dafür bedarf es Zeit und eines guten Bauplans: Die Türme auf dem Kirchberg wachsen langsam. Ob die Prinzipien rechtsstaatlichen Strafrechts mit ihnen wachsen?

Luxemburg im Februar 2008

Stefan Braum 